\title{
Considerações sobre a elaboração de um instrumento de pesquisa virtual para investigar a consciência textual no ensino do gênero textual conto
}

\section{Considerations on the establishment of an instrument of virtual research to investigate the textual consciousness in teaching the genre short story}

Doutorando no Programa de Pós-Graduação em Letras. Pontifícia Universidade Católica do Rio Grande do Sul - PUCRS, Porto Alegre, Brasil.

E-mail: professorleoprado@gmail.com
RESUMO: No presente artigo, tem-se o ensino e a aprendizagem entrecruzados na elaboração de um instrumento de pesquisa fundamentado pela Psicolinguística e o ensino de leitura. Cabe à Psicolinguística o estudo das conexões entre a linguagem e a mente e seu espaço entre os estudos sobre a linguagem percebida pelo ângulo da cognição no que se refere ao processamento da compreensão leitora e da produção escrita. Nessa perspectiva, os estudos sobre o ensino de leitura e escrita investigam a consciência textual dos leitores para verificar em que medida este processo cognitivo acontece. Nessa perspectiva, o presente trabalho propõe a análise de um instrumento de pesquisa que investiga a consciência textual do gênero conto de professores, levando em consideração os diversos elementos linguísticos que constituem o texto e estabelecem suas relações com o contexto. Para investigar a consciência textual do conto, propõe-se o enfoque sobre a coesão lexical e gramatical bem como sobre a coerência textual e a superestrutura. 0 público-alvo a que se destina o instrumento da pesquisa são professores de português que atuam nas diferentes redes de ensino da educação Básica. Espera-se que as respostas ao instrumento possam apontar como se dá o processamento da compreensão leitora daqueles que ensinam a leitura de um texto literário na escola.

Palavras-chave: Leitura; Psicolinguística; Consciência; Conto

ABSTRACT: In this article, teaching and learning are intercrossed in the development of a research instrument for Psycholinguistics and teaching reading. Psycholinguistics the study of connections between language and the space between mind and studies on the language perceived by the angle of cognition in relation to the processing of reading comprehension and writing production. In this perspective, studies on the reading and writing teaching investigate the textual consciousness of readers to verify to what extent this cognitive process takes place. In this perspective, this paper proposes the analysis of a survey instrument that investigates the textual consciousness of the genre short story, taking into account the different linguistic elements that make up the text and establish relations with the context. To investigate the textual awareness of the short story, it is proposed to focus on lexical and grammatical cohesion and on the textual coherence and superstructure. The target audience for which it is the research instrument are Portuguese teachers working in different school systems of basic education. It is hoped that the answers to the instrument can point out how is the process of reading comprehension of those who teach reading a literary text in school.

KEYworDs: Reading; Psycholinguistics; Consciousness; Short story 


\section{Considerações iniciais}

esquisadores do campo da linguagem têm demonstrado interesse pela consciência linguística, especialmente no que se refere ao diálogo entre os diferentes níveis de consciência (fonológica, morfológica, lexical, sintática, pragmática e textual) e o processamento da compreensão leitora e da produção escrita. Não obstante, este interesse se estende também para os meios de divulgação dos textos nos quais a leitura é feita.

O presente artigo mantém o foco de interesse sobre a consciência textual, porém o principal objetivo é apresentar um instrumento de pesquisa feito para traçar o perfil de professores da área de Letras que trabalham nas redes de ensino. 0 intuito é verificar o conjunto de características ou competências necessárias desses professores no seu desempenho de leitura. Este perfil tem foco específico no que se refere à compreensão leitora de contos, bem como na experiência dos investigados com esse gênero textual.

Assim, para que seja feita a análise do instrumento, primeiro, é preciso estabelecer um panorama teórico que fundamente o nível de consciência linguística, no caso, a consciência textual. Depois, apresentar como é possível tecer considerações a respeito do processamento da leitura através da análise dos níveis de consciência textual de indivíduos formados para ensinar leitura.

Uma vez que o professor é o parâmetro de aprendizagem para seus alunos, ele deve ser público-alvo do instrumento proposto, pois o processo de aprendizagem subjaz o processo de ensino. Assim, aquilo que o professor ensina está fundamentado por aquilo que ele sabe. Nesse sentido, um questionamento que suscita desse processo é: O sujeito responsável pelo processo de ensino da leitura compreende o texto que ele utiliza neste processo? O professor consegue compreender o texto que utiliza para o ensino de leitura?

A opção pelo gênero conto deve-se ao fato de que é sabido que os gêneros textuais com predominância narrativa estão presentes em muitos manuais didáticos e, portanto, precisam de atenção no processo de ensino e aprendizagem. Além disso, o conto é um gênero textual literário possível de ser usado em sala de aula por ter uma extensão cabível dentro do tempo do período de uma aula. Outro aspecto diz respeito ao fato de ele oferecer pouco custo e eliminar a necessidade de recursos externos para sua utilização tais como: biblioteca da escola, aquisição de obras, gastos que normalmente inviabilizam o uso de materiais literários na sala de aula.

Este instrumento faz parte de um grupo de outros instrumentos que juntos constituem um recorte de tese de doutorado (mesmo autor deste texto) em andamento na área da Psicolinguística que tem como objetivo investigar o processamento da compreensão leitora. 0 instrumento é um piloto cuja aplicação ainda está sob análise e, caso seja aprovada, será feita exclusivamente com professores e estagiários da área de Letras através de ferramenta on-line.

Assim, este artigo se organiza da seguinte forma: na primeira seção do texto, estão postuladas as fundamentações teóricas para ensino de leitura numa perspectiva psicolinguística, enfatizando os processos envolvidos na leitura, as estratégias de leitura, os elementos constituintes da consciência textual. Na segunda seção, estão apresentadas as concepções do gênero textual conto a partir de um viés literário prescritivo que mostra como a estrutura do texto do conto se organiza. Em seguida, uma breve explanação sobre instrumentos e sua elaboração para fins de pesquisa. E, por fim, uma análise e discussão entrecruzando a estrutura do instrumento com os aspectos teóricos implícitos nele para a investigação. 


\section{Processamento e compreensão leitora}

Inicialmente, para a elaboração de instrumento de pesquisa, precisa-se definir a perspectiva teórica que norteia a pesquisa. No presente artigo, a Psicolinguística determina a base teórica da investigação, pois atenta para aspectos como a compreensão leitora, a atenção e a consciência textual entre outros. Em interface com a Linguística do Texto e as Neurociências, tal perspectiva teórica foca no processamento cognitivo da leitura com ênfase em desenvolver estratégias cognitivas e metacognitivas.

A leitura não é uma atividade apenas de decodificação, em que o leitor apreende a "mensagem" do autor, mas é processo constitutivo do texto com base na interação autor-leitor (SOARES, 1991). Ou seja: o texto não preexiste à sua leitura, pois esta é construção ativa de um leitor que, de certa forma, "reescreve" o texto, determinado por seu repertório de experiências individuais, sociais, culturais.

O texto não deve ser visto como um simples conjunto de elementos gramaticais, nem como um repositório de mensagens e de informações (KLEIMAN, 1996) e a leitura é vista como um processo cognitivo que pode ocorrer interativamente de forma ascendente - bottom-up - e de forma descendente - top-down (SCLIAR-CABRAL, 2008).

$\mathrm{O}$ processamento ascendente se realiza das unidades menores para as maiores, com a atenção do leitor se dirigindo para as pistas visuais do texto. De modo geral, esse processamento é utilizado em situações nas quais o leitor tem poucos conhecimentos prévios sobre o conteúdo ou a linguagem do texto, o objetivo da leitura exige uma abordagem minuciosa e o texto para ler é complexo, exigindo atenção cuidadosa.

0 processamento descendente se realiza das unidades maiores para as menores, com o leitor se apoiando nas informações extratextuais. De modo geral, esse processamento é utilizado quando o leitor tem conhecimentos prévios sobre o assunto e a linguagem do texto, seu objetivo exige uma leitura geral e a densidade do texto não oferece dificuldades grandes de compreensão.

A combinação dessas formas está baseada num conjunto de variáveis: intervenientes no processamento da leitura tais como: conhecimentos prévios do leitor e estilo cognitivo; gêneros textuais literários e não literários com predominância narrativa, descritiva, expositiva, argumentativa, injuntiva; além, é claro, dos processos de Coesão, Coerência e Superestrutura que dão unidade e sentido ao texto.

Durante a leitura, o leitor utiliza estratégias de leitura (PEREIRA, 2010) como: skimming (leitura geral e rápida para uma aproximação inicial ao texto); scanning (leitura de busca de uma informação específica no texto); leitura detalhada (leitura minuciosa dirigindo a atenção para todos os detalhes); predição (antecipação do conteúdo do texto, com base nas pistas linguísticas e nos conhecimentos prévios); automonitoramento (observação, pelo leitor, do próprio processo de leitura); autoavaliação (verificação, pelo leitor, da adequação das hipóteses de leitura levantadas); autocorreção (alteração, pelo leitor, das hipóteses formuladas, caso constate inadequações).

É preciso entender que essas estratégias são mecanismos que o leitor utiliza para ativar seus conhecimentos prévios, selecionar informações no texto, realizar inferências, antecipar e localizar informações no texto, articular relações textuais e contextuais, e também construir e generalizar informações. Com isso, o uso de estratégias faz com que o leitor no processo da leitura interaja com as informações trazidas da organização social, pois o leitor, ao estabelecer relações com o texto, interage com a sua própria realidade, ampliando-a, modificando-a, percebendo-a de maneira mais nítida.

Além disso, através dessas estratégias o leitor manipula os elementos linguísticos do texto e os elementos extratextuais. Os elementos linguísticos abrangem os fônicos (fonemas/letras, ritmo, entonação), os morfossintáticos 
(limites de palavra e frase, estrutura vocabular, elos gramaticais), os semânticos (léxico, significação vocabular, elos lexicais), os pragmáticos (situação de uso), os textuais (superestrutura, coerência, coesão). Os elementos extratextuais estão nos conhecimentos prévios do leitor, em seus arquivos de memória, e no contexto.

O paradigma de ensino da leitura constitui um conjunto de concepções dos fundamentos expostos. A compreensão do que é lido e o seu processamento cognitivo, por exemplo, são marcados pela situação de leitura. Assim, os critérios para a seleção do texto que se quer investigar são importantes e devem considerar suas características como gênero (BAZERMAN, 2009) a fim de atender aos interesses pedagógicos do ano escolar considerando o planejamento definido pela escola, os objetivos de leitura e os conhecimentos prévios dos alunos.

É importante que seja estabelecido claramente o objetivo de leitura considerando essas concepções. A opção por um texto com sequências descritivas, narrativas ou argumentativas dominantes (ADAM, 2008) revelam as necessidades de que procedimentos de leitura são os mais adequados a serem usados e explicitados.

A compreensão do texto tem suporte nos seus elementos linguísticos, isto é, nos constituintes fônicos (ritmo, rima, aliteração), morfológicos (limite e estrutura dos vocábulos, classes gramaticais, flexões), sintáticos (limite e estrutura das frases/versos, paralelismo, combinações entre os segmentos), léxico-semânticos (vocábulos e seus significados, paralelismo), pragmáticos (relações entre o texto e a situação comunicativa) e textuais (superestrutura, coerência e coesão). Assim, qualquer proposta de leitura deve passar por uma análise linguística criteriosa do texto para que se possa alavancar o entendimento do texto e alicerçar sua compreensão.

Como já afirmado, são variáveis intervenientes no processamento da Leitura os conhecimentos prévios do leitor, os gêneros textuais con- sumidos que podem ser literários e não literários, a predominância por uma tipologia textual seja ela narrativa, descritiva, expositiva, argumentativa, injuntiva; os processos de Coesão, Coerência e Superestrutura, bem como estratégias de leitura tais como: Skimming, Scanning, Predição, Inferência, Leitura detalhada, Automonitoramento, Autocorreção e Avaliação.

É importante destacar que as variáveis citadas ocorrem no ato da leitura em si e é a partir destes fenômenos que se pode observar e fazer ilações a respeito de como o processamento da leitura acontece cognitivamente. Assim, uma atividade de leitura sobre um gênero textual qualquer aciona todos esses conhecimentos que levam à compreensão ou não do texto e da informação que ele traz.

A consciência textual é um dos níveis da consciência linguística que pode ser percebida através da leitura. No entanto, é necessário primeiro entender o conceito de consciência antes de apontar as nuances linguísticas que mais interessam a este estudo.

Baars (1997) define consciência como uma habilidade que permite acessar, disseminar e trocar informações, assim como exercer controle e coordenação. Já Sternberg (2000) destaca que experimentar a percepção consciente tem relação com o foco da atenção, assim como o próprio conteúdo da consciência. Em vista disso, pode-se perceber que a consciência é a apropriação de uma dada informação que depende da atenção.

Consciência textual é uma atitude reflexiva do indivíduo sobre o seu objeto de análise (o texto) de forma deliberada cujo foco atencional é o próprio texto (GOMBERT, 1992). A consciência textual está centrada no monitoramento e na atenção à coesão, à coerência e à superestrutura do texto (ibidem).

Para o entendimento do que é coesão, esta pesquisa atém-se para a definição estabelecida por Halliday e Hasan (1976), que afirmam ser ela o 
processo que estabelece as relações de sentido que existem no interior do texto e que o definem como tal.

Os mecanismos de coesão por esses autores definidos são: repetição, sinonímia, associação por contiguidade e superordenado que compreendem a coesão lexical; referenciação, elipse e conjunção que compreendem a coesão gramatical.

Charolles (1978) é o autor definido para dar fundamentação ao que se deve entender por coerência para este estudo. Segundo ele, a coerência se refere à possibilidade de instauração de um sentido ao texto, isto é, está relacionada à significação global. Pode-se considerar que coerência é a relação que um texto tem com o conhecimento de mundo de quem o lê.

São constituintes da coerência a Manutenção temática, a Progressão temática e a Ausência de contradição interna que dizem respeito respectivamente a manter o texto no mesmo assunto, apresentar informações novas dentro desse assunto e não introduzir elementos que contradigam ou tornem esdrúxulas as informações apresentadas.

Quanto à Superestrutura, adota-se aqui Van Dijk (2004), que a define como a estrutura esquemática convencional do texto, pois ela seria uma forma global que organiza o conteúdo global do texto, isto é, a macroproposição. Com esta definição pode-se entender porque um determinado leitor é capaz de entender a diferença entre uma receita e uma reportagem ao, apenas, se deparar com elas sem necessidade de detalhamento de informações contidas no texto.

Os conceitos teóricos apresentados até este ponto do texto embasam os conhecimentos necessários para a elaboração das questões do instrumento de pesquisa. Uma vez que o sujeito investigado responder a este instrumento, pode-se tentar estabelecer em que medida ele domina os conhecimentos explorados nas questões do instrumento.
Na próxima seção do texto, estão os conceitos referentes ao conto enquanto gênero textual literário. A percepção teórica do conto também se relaciona com a investigação proposta pelo instrumento e contribui para o entendimento do processamento da leitura do texto.

\section{0 gênero textual conto}

Nesta seção do texto, pretende-se estabelecer as definições sobre conto que norteiam a pesquisa e a elaboração dos instrumentos para mesma. Antes de tratar do conto propriamente dito, precisa-se tratar de gênero textual a fim de se entender como um determinado texto pertence aos domínios de um determinado gênero.

Parece tarefa bastante difícil separar texto de gênero textual, atualmente, e, especialmente, definir sobre qual tratar primeiro, uma vez que, evidentemente, texto e gênero textual parecem ser duas faces de uma mesma moeda e que depende do pesquisador escolher por qual face começar.

Gêneros textuais definem-se principalmente por sua função social, pois são textos que se realizam por uma (ou mais de uma) razão determinada em uma situação comunicativa (um contexto) para promover uma interação específica. Trata-se de unidades definidas por seus conteúdos, suas propriedades funcionais, estilo e composição organizados em razão do objetivo que cumprem na situação comunicativa.

Uma das principais características dos gêneros é o fato de serem enunciados que apresentam relativa estabilidade (BAKHTIN, 2000). É esse aspecto que permite, justamente, com que sejam compreendidos. Assim, no momento em que um texto é produzido, um gênero se apresenta neste texto em função do que se pretende comunicar; em função do efeito que se deseja produzir no interlocutor; em função da ação que se pretende produzir no meio em que o texto se inscreve. 
O conto é um gênero textual do campo literário que pretende comunicar algo e causar um efeito em seu interlocutor, neste caso, o leitor, pois tal efeito comunicado pode produzir uma ação no mundo. É importante destacar que um texto literário é um recorte artístico de uma época, ele revela as nuances da sociedade do período que retrata e, portanto, sendo um texto narrativo tem suas marcas relativamente estáveis.

Segundo Gotlib (1990), a história do conto pode se esboçar a partir de um critério de invenção, que foi se desenvolvendo. Primeiro, houve a criação do conto e sua transmissão oral, depois, ocorreu o seu registro escrito. E só então, a criação de contos por escrito. Quando o narrador assumiu a função de contador, criador, escritor de contos, o seu caráter literário passou a existir. E, além disso, a voz desse narrador pode interferir no seu discurso. 0 modo de contar e os detalhes do modo como se conta caracterizam o repertório discursivo do narrador.

O narrador é uma criação do escritor, e este é, portanto, "ficção de uma voz". A voz que fala ou escreve só se afirma enquanto contista quando existe um resultado de ordem estética, ou seja: quando consegue construir um conto que ressalte os seus próprios valores enquanto conto. Estes embriões do que pode ser uma arte só se consolidam mesmo numa obra estética quando a voz do contador se transforma na voz de um narrador: Os outros estão atravessados na voz desse narrador que fala, sua voz não é só sua, mas do escritor por detrás dele e de todas as vozes que formam este escritor.

Um gênero textual é delimitado pelos modos variados de narrar uma história com pontos característicos, por exemplo, romances, poemas ou dramas. Para cada gênero um público a ser destinado o texto e um repertório de procedimentos ou normas a ser usado. Pode-se misturar características dos vários gêneros e até dissolver a própria ideia de gênero e de normas. Há ainda períodos em que os limites que definem o que pertence a um ou outro gênero se embaralham.
A denominação ao texto conto tem nuances interessantes, pois é oriunda do inglês Novel, terminologia usada num período que foi do século XVI ao XVIII, que se caracteriza pela prosa narrativa de ficção com personagens ou ações representando a vida diária, diferenciando-se de uma forma mais longa e mais tradicional, o romance (GOTLIB, 1990). Segundo a autora, no século XIX, com o declínio do romance antigo, a novel preencheu o espaço disponível, perdeu as associações originais, deixou de ser breve, virou romance. E só no século XIX surge um termo específico: short-story para designar a história curta.

Ainda, conforme Gotlib (1990), modernamente, sabe-se que a fábula é o texto literário bastante breve que traz personagens animais com características humanas e o objetivo é sempre instruir. Assim como a parábola, que tem sentido realista e moralista e apresenta homens como personagens. Em ambos, o sentido não é aparente e os detalhes de personagens podem ser simbólicos. $\mathrm{O}$ conto conserva características destas duas formas: a economia do estilo e a situação e a proposição temática resumidas.

No espanhol, atualmente, romance é novela, Novela é novela corta. E conto é cuento. No francês, nouvelle é uma forma mais complexa com mais cenas, apresentando série de incidentes para análise e desenvolvimento da personagem ou motivo; conte é mais concentrado, com episódio principal e frequentemente com elementos de fantasia. No alemão, surge a necessidade de um termo para designar a narrativa realmente curta, pois a novelle tem desenvolvimento linear, com um ponto de interesse chocante, mas se torna mais extensa. São os americanos que afirmam o termo short story, designando não somente uma estória curta, mas um gênero independente (GOTLIB, 1990).

As formas híbridas, incentivadas no século XIX, podem conservar mais ou menos o caráter épico do conto. 0 conto em verso traz "um universo verbal que imita ações e pessoas, que organiza um argumento, que relaciona 
componentes". Pode ser recontado, indefinidamente, legitimando sua condição narrativa e preservando as características consideradas chaves do conto:

Há três elementos constitutivos do conto segundo Gotlib (1990): o impulso único, a tensão unitária e o efeito preciso. 0 impulso único; no conto se caracteriza pelo enredo que tem sempre um objetivo preciso e não se desenvolve através de muitas caracterizações de espaço e tempo. Não há rodeios naquilo que se quer apresentar. A tensão unitária se caracteriza pela ausência de vários conflitos, mas de um somente. E, por conta, disso, não se vê muitos personagens. Quando isto ocorre, eles estão todos imbricados pelo mesmo conflito. $\mathrm{O}$ efeito preciso e inesperado se caracteriza no conto por sua natureza impactante. Ele é concebido para impactar, transformar psiquicamente a personagem central e causar no leitor uma sensação de golpe, impacto, susto, surpresa.

Estes conceitos podem ser esclarecidos no que Adam (2008) determina como estrutura hierárquica nos textos narrativos constituída de cinco macroposições narrativas as quais ele chamou momentos do aspecto: 1) antes do processo ou situação inicial; 2) início do processo ou desencadeador; 3) curso do processo ou avaliação; 4) fim do processo ou resolução; e 5) depois do processo ou situação final. 0 impulso único seria o desencadeador enquanto que a tensão unitária seria o curso do processo. Já o efeito preciso e inesperado se constitui como a resolução.

As categorias de Adam foram estabelecidas para os textos com tipologia narrativa. Assim, sendo o conto um texto breve sem muitas caracterizações, cabe salientar que ele compreende a tipologia narrativa, mas não necessariamente apresente os movimentos situação inicial e final, pois ele tende a ultrapassar essas etapas indo direto ao ponto.

No entanto, o que faz o conto é o modo pelo qual ele é narrado, pois isto torna cada um de seus elementos algo importante no panorama que a narrativa constrói, tornando-o atrativo ou não. "Sim, em literatura a ordem dos fatores altera o produto" (GOTLIB, 1990, p. 9).

O conto, como obra literária em si, é produto de um trabalho consciente, que se faz por etapas, em função de uma intenção: a conquista do efeito único, ou impressão total. A construção deste texto obedece a uma precisão minuciosa.

Como se pode observar, o impulso único, a tensão unitária e o efeito preciso e inesperado caracterizam os traços que distinguem o conto dos demais gêneros do discurso. Nas próximas seções do artigo, está uma possível relação entre os conceitos de Bakhtin e outros que determinam o gênero, além de, alguns exemplos para ilustrar tais asserções.

As considerações feitas até aqui servem para embasar o que se entende por conto neste artigo e o que se pretende investigar ao se elaborar um instrumento que o investigue. Na próxima seção, estão as formas de se elaborar um instrumento de pesquisa.

\section{A elaboração de instrumentos}

O instrumento de pesquisa sobre o qual este artigo discorre tem como objetivo traçar um perfil do professor que ensina leitura na escola utilizando textos do gênero conto. Como ele foi desenvolvido para ser aplicado em ambiente virtual, isto é, a pessoa que o responde o acessa na internet e não há o atravessamento direto do pesquisador junto ao pesquisado, ele mescla dois formatos de instrumento: a entrevista e o questionário. Assim, antes de analisar o instrumento propriamente é preciso tecer algumas considerações sobre entrevista e sobre questionário.

Segundo Lakatos e Marconi (2008, p. 278), a entrevista é "uma conversação efetuada face a face, de maneira metódica, que pode proporcionar resultados satisfatórios e informações necessárias" e tem como 
objetivo compreender as perspectivas e vivencias dos participantes. Esse instrumento de coleta de dados, segundo Ludwig (2008), possui três tipologias: 1) não estruturada, que conta com questões abertas, sem rigidez de sequência e número reduzido; 2) estruturada, cujas questões são específicas e nitidamente ordenadas; 3) semiestruturada, que se baseia em questões específicas, porém sem ordenamento rígido.

As entrevistas compreendem o encontro entre duas ou mais pessoas, com vistas à obtenção de informações a respeito de determinado assunto, utilizando-se para isto de uma conversação sistematizada de natureza técnico-profissional. Seus objetivos geralmente são: averiguação de fatos; investigação de opiniões sobre fatos; identificação e descrição de sentimentos; identificação de percepções pessoais; identificação de planos de ação; investigação de condutas atuais e/ou passadas. Entrevistar é um procedimento utilizado na investigação social para coleta de dados, com finalidade de fornecer subsídios para diagnósticos, análises, pesquisas ou mesmo com a finalidade de discutir e buscar soluções para alguma problemática específica.

A vantagem na utilização de entrevistas está no fato de que ela: pode ser usada com qualquer segmento da população; propicia melhor amostragem da população-alvo; oferece maior flexibilidade e possibilidades de repetir e esclarecer as questões; oportuniza maior aprofundamento para avaliar atitudes e condutas do entrevistado; contribui para obter dados que não são facilmente encontrados em fontes documentais e que são relevantes e significativos para a pesquisa; permite a quantificação dos dados e posterior tratamento estatístico; propicia a captura de subjetividades inseridas no discurso do entrevistado.

A elaboração de uma entrevista compreende algumas fases:

1) Planejamento da entrevista (roteiro, questões, etc.);

2) Pré-testagem do instrumento;
- Aplicação em população-piloto semelhante;

- Validação;

- Fidedignidade;

- Operacionalidade;

- Estimativa de resultados.

3) Conhecimento prévio do entrevistado em relação ao assunto;

4) Agendamento explicitando data, hora e duração provável;

5) Garantia ao entrevistado do sigilo das informações;

6) Registro das respostas (gravando, filmando, combinações com registro escrito).

No entanto, o uso de entrevistas apresenta limitações tais como: dificuldades de expressão e comunicação de ambas as partes; possibilidade de influência do entrevistado, consciente ou inconscientemente, pelo entrevistador; dependência da disposição do entrevistado em dar opiniões, informações ou dados relevantes; características do contexto no qual o entrevistado esteja inserido em relação às informações que vai prestar (medo de ser identificado); controle pequeno sobre a coleta de dados; demanda um tempo muito grande, nem sempre disponível.

Diferentemente da entrevista, o questionário é um instrumento de coleta de dados, constituído de uma série ordenada de perguntas, que devem ser respondidas por escrito e sem a presença do entrevistador.

De um modo geral, o questionário deve: 1) considerar tipos, ordem, grupos ou categorias de agrupamento das questões; 2) limitar a extensão do questionário de modo a propiciar a totalidade das respostas em um tempo estipulado; 3) codificar as questões para facilitar a tabulação posterior; 4) elaborar instruções definidas e metas explicativas de preenchimento e dos objetivos do instrumento; 5) observar aspecto material e estético do instrumento, de modo a facilitar a manipulação, leitura das perguntas e respectivas respostas; 6) estabelecer um critério consistente de elaboração 
das perguntas, tomando como base a técnica do funil - partir do mais geral para o mais específico e evitar o efeito contágio - questão anterior contaminando a subsequente.

O questionário também apresenta limitações tais como: dificuldades de expressão e comunicação escrita de ambas as partes pode gerar respostas inadequadas; demora na coleta dos questionários distribuídos, podendo atrasar a pesquisa; dependência da disposição do respondente em responder, por escrito e com fidedignidade à situação investigada; demanda de tempo de quem responde nem sempre disponível.

A entrevista é importante para esta pesquisa porque serve como modelo para estruturar o instrumento de pesquisa a ser aplicado nos professores. As informações oriundas desse instrumento servirão para se estabelecer o perfil do grupo de professores a fim verificar em que medida as características dos sujeitos contribuem para evidenciar maior ou menor grau de compreensão leitora do texto investigado.

\section{Perfil do professor: um instrumento de investigação da consciência textual}

Ao longo do texto que precede esta seção, alguns conceitos foram trazidos para reflexão e embasamento a respeito do processamento cognitivo da leitura, assim como, para a sustentação do conto enquanto texto e gênero textual e, também, para a elaboração de instrumentos de pesquisa como entrevistas e questionários. O propósito dessas conceituações é justificar e embasar a elaboração de um instrumento de pesquisa que traça o perfil de professores, tentando mensurar o nível de consciência textual do conto.

Neste ponto do texto, será apresentada uma descrição do instrumento elaborado a fim de relacionar cada item que o compõe com as aspirações teóricas que ele propõe investigar. Assim, poderão se estabelecer percepções sobre o uso de um texto literário em sala de aula com a finalidade de se conduzir uma investigação linguística do mesmo, estabelecendo uma interface entre literatura e linguística, através da perspectiva psicolinguística na qual se pode estudar o processamento da leitura, a compreensão leitora e a consciência textual.

Na seção anterior, foram apresentadas as definições e usos tanto de entrevista quanto de questionário com a justificativa de que este instrumento, de certa forma, tange os dois formatos quando se considera sua natureza virtual. $O$ instrumento é uma entrevista, pois traz perguntas e, em algumas questões, alternativas de respostas, bem como, também é um questionário, pois elenca questionamentos cujas respostas constituem informações elementares dos sujeitos que a ele respondem.

Ainda que ele se assemelhe mais a um questionário por não ter a presença do entrevistador, ele não perde características indeléveis da entrevista tais como seu planejamento e sua natureza de identificação de algo, no caso, o conhecimento sobre um determinado assunto.

Como dito anteriormente, este instrumento é um piloto que ainda não foi aplicado, mas foi pensado para um determinado grupo e tem propósitos específicos de investigação que passam a ser detalhados na sequência do texto.

O instrumento é constituído de quinze (15) questões, onze (11) delas objetivas, com cinco (5) alternativas de resposta simples cada uma; quatro (4) delas são questões abertas nas quais o respondente escreve de acordo com suas experiências.

A questão 1 traz a pergunta: Qual o seu tempo de formação? E tem como alternativas as opções: Estou em formação; Menos de 2 anos formado(a), Mais de 2 anos formado(a); Mais de 10 anos formado(a); Mais de 20 anos formado(a).

A questão 2 apresenta a pergunta: Qual o seu tempo de experiência lecionando Língua Portuguesa? E tem como alternativas de resposta: Nunca 
lecionei; Leciono há menos de 2 anos; Leciono há mais de 2 anos; Leciono há mais de 10 anos; Leciono há mais de 20 anos.

Tanto a questão 1 quanto a 2 traçam um perfil sobre a formação dos professores investigados. Na primeira, tem-se a identificação do tempo de formação e na segunda, tem-se a experiência de ensino dos sujeitos pesquisados. Em ambas, pode-se tecer considerações a respeito das visões de ensino do sujeito, bem como em que medida essas visões se aproximam ou não das visões dos outros sujeitos. Além disso, as perguntas revelam a prática de ensino dos professores pesquisados, pois foram feitas com o intuito de evidenciar o conhecimento que o professor tem sobre o ensino de leitura de contos.

A questão 3 foca sobre as séries do Ensino fundamental e Médio que o professor mais tenha experiência de ensino. As opções variam do $6^{\circ}$ ano do Ensino Fundamental ao 3o ano do Ensino Médio, séries para as quais os professores de Português são formados para trabalhar nos cursos de Letras de todo o país. Há um campo abaixo da última alternativa no qual ele pode detalhar sua experiência caso ela não se encaixe em apenas uma série oferecida nas alternativas. Esta questão tem o objetivo de verificar em que currículo (entenda-se aqui planos de estudos da disciplina) reside a experiência do professor.

A questão 4 entra nos hábitos de leitura e canaliza para o conto: Considerando o hábito de leitura de contos, quantos contos você lê? Tendo como alternativas: 2 ou 3 no período de um mês; 2 ou 3 no período de um ano; mais de cinco no período de um ano; em toda minha vida devo ter lido 2 ou 3 contos; nunca leio contos. Essas alternativas têm por objetivo verificar a familiaridade com o gênero textual em questão e consequentemente com sua estrutura textual e respectiva consciência textual. $\mathrm{O}$ foco não é propriamente a consciência textual, mas tentar oferecer caminhos de investigação que revelem a mesma.
As questões 5 e 6 não apresentam alternativas porque questionam respectivamente sobre os cotos e os autores conhecidos. A quinta questão pede que o investigado cite, pelo menos, um conto que tenha marcado sua vida leitora e a sexta pede ao investigado que cite autores de contos que ele aprecie. Ambas buscam investigar o detalhamento do conhecimento dos professores sobre o gênero textual em questão.

Apesar de estar diretamente relacionado aos hábitos de leitura e gosto pela leitura do gênero textual de contos, as questões de 4,5 e 6, elas estão também indiretamente relacionadas ao ensino desses professores, pois o contato com o gênero familiariza o texto ao leitor e permite uma melhor abordagem deste sobre aquele. A leitura habitual de um determinado gênero permite que se desenvolva uma maior consciência textual desse gênero.

As questões do instrumento que compreendem do número 7 ao 9 estão diretamente relacionados com o ensino e o uso de contos em sala de aula. A questão 7 pede que o investigado avalie a leitura de contos em sala de aula oferecendo a ele cinco alternativas que estabelecem uma escala de percepções da própria prática bem como da prática em geral: São opções: irrelevante, pouco relevante, relevante, muito relevante, indispensável. Esta mesma questão oferece um campo de preenchimento que pede ao respondente que justifique sua resposta. Tal propósito é para verificar em que medida o professor tem consciência da importância e do próprio texto como um todo.

Ampliando a questão 7, vem a questão 8 pedindo que o professor cite contos que já tenha utilizado em sala de aula e que, na sua avaliação, são bons textos para fins pedagógicos e a questão 9 solicitando que o respondente cite autores de contos que considera bons para o uso em sala de aula. Tanto a questão 8 quanto a questão 9 não têm opções de resposta, apenas um campo de preenchimento pois ambas revelam, novamente, o conhecimento sobre $o$ gênero textual conto e sua aplicabilidade em sala de aula. 
A partir da questão 10 o instrumento começa a investigar a consciência textual do conto. Nesta, a indagação é: como você avalia o seu conhecimento do gênero textual conto? E as opções de resposta variam numa escala de percepções que são: péssimo, ruim, bom, muito bom, excelente.

Abaixo da questão há um campo de preenchimento para o qual é solicitada uma nota de 0 a 10 do respondente sobre seus conhecimentos sobre o conto. Esse mesmo campo aparece em todas as questões subsequentes naquilo que elas pontualmente questionam.

A Superestrutura do gênero textual conto é mais bem definida pelas categorias estabelecidas por Gotlib (1990) que se desdobram também nas categorias de Adam (2008) previamente apresentadas e é foco da questão 11 na qual o respondente tem que avaliar seu conhecimento numa escala que varia de péssimo, ruim, bom, muito bom e excelente.

A questão 12 indaga sobre os conhecimentos de coesão lexical que compreende os mecanismos: repetição, sinonímia, associação por contiguidade e superordenado. Nesta questão o professor também tem que avaliar seu conhecimento numa escala que varia de péssimo, ruim, bom, muito bom e excelente, além de atribuir uma nota de 0 a 10 no campo solicitado.

O mesmo procedimento de resposta da 12 se repetira na questão 13 na qual é investigada a coesão gramatical que compreende referenciação, elipse e conjunção; e na questão 14 que investiga a coerência que se refere à possibilidade de instauração de um sentido ao texto (CHAROLLES, 1978).

A questão 15 traz uma reflexão e avaliação sobre o uso do texto literário na aula de língua portuguesa e o respondente tem que decidir entre as opções: desnecessário, pouco necessário, necessário, muito necessário e indispensável.

Este instrumento foi desenvolvido através de um software online e, uma vez definidos os sujeitos que deverão respondê-lo, o mesmo é enviado por e-mail e, à medida que, vai sendo respondido, as respostas geram uma planilha de dados que fica armazenada em um servidor on-line ao qual o autor do instrumento tem acesso.

Estas planilhas serão estudadas e uma análise do material coletado será feita com o intuito de buscar pontos de convergência e divergência nas respostas para que se possam estabelecer categorias de análise. O objetivo é descobrir o quanto o sujeito investigado sabe sobre o conto para que se possa traçar considerações a respeito do ensino de leitura desse texto, pois o instrumento tem a finalidade de mensurar o que o professor sabe sobre aquilo que ensina. Com isso, será possível tecer considerações a respeito do processo de ensino e aprendizagem de leitura de textos literários.

É indiscutível que como o instrumento descrito no presente artigo ainda não foi aplicado, todas as questões que o constituem são tentativas de estabelecer um mecanismo de mensuração das questões teóricas aqui apresentadas. Da mesma forma, as expectativas de respostas são meras hipóteses sobre o ensino da leitura, o processamento da compreensão leitora bem como da consciência textual do gênero textual conto. A aplicação do instrumento poderá vir a estabelecer sua validade ou não no sentido de dar dados acurados de pesquisa.

\section{Considerações finais}

As pesquisas no campo da Psicolinguística investigam processos de compreensão. Este artigo teve como objetivo descrever um instrumento de pesquisa na referida área perpassando pelos conceitos necessários que subjazem a elaboração do mesmo. Apenas seu uso pode oferecer de fato material para análise do processamento da compreensão leitora. No entanto, a elaboração do instrumento é parte fundamental da pesquisa que se propõe, pois faz com que se pense detalhadamente sobre os conhecimentos que ele 
envolve, avaliando e precisando minimamente o que realmente deve constar na pesquisa.

Como sugestão para futuras pesquisas pode-se destacar a possibilidade de aplicação do instrumento aqui descrito junto a professores das mais diferentes redes de ensino da Educação Básica, o público para o qual ele foi elaborado. Seja como piloto ou mesmo como instrumento de fato de pesquisa sobre ensino de leitura, este instrumento pode oferecer um meio de se estabelecer uma tão sonhada interface entre Literatura e Linguística. Através do uso de gêneros textuais literários pode-se oferecer material de leitura de qualidade no ensino da língua materna.

Importante destacar ainda que este instrumento não foi desenvolvido para uma pesquisa cuja finalidade seja avaliar os processos de formação de professores. Pelo contrário, seus resultados que dele emanarem devem servir para alertar todo e qualquer profissional da educação sobre a atenção devida que se deve ter com o texto usado na sala de aula para o ensino de leitura.

Da mesma forma, o instrumento apresentado nesta pesquisa também não se pretende inquestionável ou detentor de uma fórmula absoluta para investigar o processamento da leitura. Pelo contrário, outras pesquisas dessa natureza precisam ser conduzidas a fim de que se possa mensurar com mais precisão e eficácia em que medida se dá o processamento da compreensão leitora e a consciência textual dos gêneros trabalhados em sala de aula.

\section{Referências}

ADAM, Jean M. A Linguística: introdução à análise textual dos discursos. São Paulo: Cortez, 2008.

BAARS, Bernard. J. A cognitive Theory of Conciousness. Cambridge: Cambridge, 1997. BAKHTIN, Mikail. A estética da criação verbal. São Paulo: Martins Fontes, 2000.

CHAROLLES, Michel. Introduction aux problèmes de la cohérence des textes. Langue Française. Paris: Larousse, 1978.
GOMBERT, Jean E. Metalinguistic development. Chicago: The University of Chicago Press, 1992

GOTLIB, Nádia Battella. A teoria do conto. São Paulo: Ática, 1990.

HALLIDAY, Michel A. K.; HASAN, Rugaya. Cohesion in English. London: Longman, 1976.

KLEIMAN, Ângela. Leitura e Prática Social no Desenvolvimento de Competências no Ensino Médio. In: BUZEN, Clécio; MENDONÇA, Márcia (orgs.). Português no Ensino Médio e Formação do Professor. São Paulo: Parábola, 2006. p. 23-36.

LAKATOS, Eva Maria; MARCONI, Marina A. Fundamentos de metodologia científica. São Paulo: Atlas, 2003.

LAKATOS, Eva M.; MARCONI, Marina A. Técnicas de pesquisa: planejamento e execução de pesquisas, amostragens e técnicas de pesquisa, elaboração, análise e interpretação de dados. São Paulo: Atlas, 2008.

LUDWIG, Antônio C. W. Fundamentos e prática de metodologia científica. Petrópolis: Vozes, 2009.

PEREIRA, Vera W. Pesquisa em Psicolinguística: antecedentes, caminhos e relatos. Letras de Hoje, Porto Alegre, v. 45, n. 3, p. 48-53, jul.-set. 2010.

SCLIAR CABRAL, L. Introdução à Psicolinguística. São Paulo: Ática, 1991.

SOARES, Magda. Prefácio. In: DELL'ISOLA, Regina L. P. Leitura: inferências e contexto sociocultural. Belo Horizonte: Imprensa Universitária, 1991.

STERNBERG, Robert J. Psicologia Cognitiva. Porto Alegre: Artes Médicas Sul, 2000. VAN DIJK, Teun. Cognição, discurso e interação. São Paulo: Contexto, 2004.

Recebido em 25/04/2016.

Aceito em 31/08/2016. 